\title{
Notions of Creativity in Mathematics Education Research: a Systematic Literature Review
}

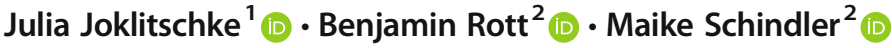

Received: 25 August 2020 / Accepted: 31 May 2021 / Published online: 3 August 2021

(C) The Author(s) 2021

\begin{abstract}
Interest in creativity in mathematics education research is increasing, and the field of research is growing. Yet, research on creativity and the notions (we use this wording to accumulate understandings, beliefs, and ideas about the construct) of creativity that are addressed in empirical research are diverse and difficult to organize in an overview, with different theoretical backgrounds and theoretical assumptions underlying them. The aim of this article is therefore to provide a systematic overview of notions of creativity addressed in recent empirical research on mathematical education. We conducted a systematic literature review, guided by the question, What notions of creativity are addressed in current mathematics education research and what theoretical foundations do they rely on? The article gives an overview of the five predominant notions of creativity that were identified in current empirical research in mathematics education from 2006 to 2019. We describe and evaluate these notions and identify trends that will help to structure this diverse field of research.
\end{abstract}

Keywords Mathematical creativity · Notions · Systematic literature review · Theories

Research on creativity is attracting growing interest (Hersh \& John-Steiner, 2017; Runco, 2014). Albert and Runco (1999) point out that "at present the field [of creativity] can only be described as explosive" (p. 17). Moreover, the rapid development of society (e.g. in the field of digitalization or artificial intelligence) has consequences for everyone (National Council of Teachers of Mathematics, 2005) - professions change and disappear, and completely new ones emerge (Barak, 2009). The required professions often become more complex, and, especially in the field of mathematics (e.g. applied mathematics), creative solutions are sought to solve problems

Julia Joklitschke

Julia.joklitschke@uni-due.de

1 Faculty of Mathematics, University of Duisburg-Essen, Thea-Leymann-Straße 9, 45147 Essen, Germany

2 University of Cologne, Cologne, Germany 
more efficiently (Clements, 2013). Mathematics educators aim to prepare students for their present and future lives in increasingly automated and interconnected societies and economies (OECD, 2014) - and, in turn, mathematics education research often addresses creativity (see, e.g. Leikin \& Pitta-Pantazi, 2013; Schindler \& Lilienthal, 2020; Sheffield, 2013; Singer, 2018).

Looking at research on creativity in mathematics education, there is a multitude of different aspects to be studied as well as many underlying theoretical assumptions on creativity (Leikin \& Sriraman, 2017b; Pitta-Pantazi et al., 2018; Sriraman, 2009). At this point, we will introduce the term notion. By notions, we mean ideas, beliefs, and understandings (Oxford University Press, 2019) of a certain construct, and for the paper at hand, we include under this term all the ideas, beliefs, and (theoretical) understandings about the concept creativity. For example, some scholars focus on creative products (e.g. Kattou et al., 2015), while others focus on creative processes (Lithner, 2008). Theoretically, some researchers are inspired by theories from the domain of psychology (e.g. Leikin et al., 2011), whereas others draw on mathematical stage theories (e.g. Liljedahl, 2013). The body of research on creativity in mathematics education research is rich and diverse (Leikin, 2009; Schindler \& Lilienthal, 2020; Sriraman, 2005).

Given the diversity of mathematics education research on creativity, it is difficult for researchers to summarize the ways in which creativity and its respective, underlying theories is understood; the landscape of mathematics education research on creativity is broad-spanning and heterogeneous. Yet, for the field to develop and for new studies to build on other research, it is important for researchers to understand and overview the general field. For that reason, researchers in mathematics education have begun to sort and map existing studies. For example, Pitta-Pantazi et al. (2018) organized research on mathematical creativity, drawing on classifications provided by Rhodes (1961). Rhodes (1961) identifies four different "strands," or perspectives on creativity, which he calls the 4 Ps of creativity: Creativity can be seen as a feature of either a person, a process, press, or a product. When creativity of persons is regarded, the person as an individual and their characteristics are in focus. Processes refer to ways of thinking. Rhodes refers to ideas such as Wallas' (1926) model of preparation, incubation, illumination, and verification to account for creativity as a process. Rhodes uses the word press to emphasize the interplay between individual and environment, positing that people in a vacuum cannot be creative; they respond to external pressures. The fourth strand, product, focuses on newness and assigns creativity to outcomes or products. However, these strands are not separate from one another. Rhodes stresses that "each strand has unique identity academically, but only in unity do the four strands operate functionally. It is this very fact of synthesis that causes fog in talk about creativity" (Rhodes, 1961, p. 307). His comment about the confusion and ambiguity caused by the interaction of the strands hints at the need for researchers to communicate clearly which strands of creativity and which interplays they investigate. Pitta-Pantazi et al. (2018) use Rhodes' categorization and apply it successfully to mathematics education by showing how existing studies can be mapped based on Rhodes' categories, addressing processes, persons, press, and products. By doing so, they investigate what researchers "have learned so far on mathematical creativity" (Pitta-Pantazi et al., 2018, p. 28). Yet, they clarify that they "do not attempt a summative review or a meta-synthesis of what is known" (Pitta-Pantazi et al., 2018, p. 28) and do not claim their overview to "be 
exhaustive or comprehensive" (Pitta-Pantazi et al., 2018, p. 28)-leaving room for a systematic review of the research in mathematics education on creativity to be conducted.

Additionally, Sriraman (2009) has provided an overview of "contemporary models of creativity from psychology [that were] reviewed and used to interpret the characteristics of mathematical creativity" (p. 13). To empirically investigate the mathematical creativity of mathematicians, Sriraman conducted a survey of the approaches that are used in the study of creativity in psychology. Drawing on Sternberg and Lubart's (1999) work in the domain of psychology, he identifies six approaches: the mystical approach (where creativity is associated with inspiration and/or a spiritual process), the pragmatic approach (which focuses on developing creativity), the psychodynamic approach (where creativity is seen to arise from the interplay of the conscious and unconscious mind), the psychometric approach (which focuses on measuring creativity), the cognitive approach (which focuses on cognitive processes involved in creativity), and the social-personality approach (with emphasis on personality, motivation, and the socio-cultural context). Sriraman's systematization of approaches in the study of creativity in psychology has been a valuable foundation for the study of creativity in mathematics education for many years. Yet, it has not been used to review the research on creativity in mathematics education itself. We feel that now, 10 years after Sriraman's survey, with increasing numbers of studies on mathematical creativity within this time span, it would be valuable to review what such understandings or notions of creativity may look like in the domain of mathematics education. Looking at the two reviews, it is noticeable that they were prepared in a typical way - on the one hand, they give a good overview, and on the other hand, no information can be found about the extent to which the literature collection was carried out and whether the respective overviews are considered complete.

Further efforts to review creativity in education was made by Wyse and Ferrari (2015), who compared existing curricula "of the 27 member states of the EU (EU 27) and in the UK" (Wyse \& Ferrari, 2015, p. 30) for the significance and explicit discussion of creativity. They focused on how often creativity appears in the different curricula in Europe (EU-27) and found that the term creativ* in mathematics is seldom mentioned (with a ratio of 0.17 in comparison to the average of all subjects under investigation) - indicating a low significance of creativity in curricula across Europe. Despite Pitta-Pantazi et al.'s (2018), Sriraman's (2009), and Wyse and Ferrari's (2015) overviews, we feel that there is a need to map existing research on creativity in mathematics education and to provide a comprehensive and entire overview of what notions of creativity are under investigation in current mathematics education research on creativity and what theoretical foundations they rely on.

The aim of our article is to provide a systematic overview of notions of creativity addressed in recent empirical mathematics education research. We do not want to pursue this goal only to do research, but we also want to indicate and infer that depending on how someone understands and defines creativity, different consequences may result: for the assessment of creativity or and the support of students. Therefore, we want to systematically unfold the variety of mentioned notions in this field. We conducted a systematic literature review, since literature reviews can provide a comprehensive overview of a specific research topic (Royal Literary Fund, 2020; The Writing Center, 2020), and follow Pitta-Pantazi et al. (2018) in their efforts to make 
advances in the field through looking back at what has been addressed in research on mathematical creativity so far. We present a literature review that systematically compiles current research on creativity in mathematics and ask the research question, What notions of creativity are addressed in current mathematics education research and what theoretical foundations do they rely on? Through pursuing this question, we aim to capture the landscape of research on creativity in mathematics and contribute to the body of research through providing such an overview (Jones \& Tzekaki, 2016).

\section{Method}

For our systematic literature review, we follow the approach by Gough et al. (2013), which was originally developed for the field of politics and has been transferred to mathematics education by Nilsson et al. (2018). More precisely, we conduct what Gough et al. call a configurative review: a review conducted to develop ideas or theories inductively from the literature under investigation, focusing on the heterogeneity and diversity of the articles involved. This approach comprises ten steps which are explained below. ${ }^{1}$

\section{Steps 1 and 2: Needs and Review Question}

The need for our systematic review and its research question were described in the introduction of the article.

\section{Step 3: Scope}

Before searching for literature, it is important to determine a number of parameters to "[establish] the criteria used to select studies" (Gough et al. 2013, p. 11). To take into account the quality of articles in our review, we chose to only include (1) peer-reviewed journal articles. We also only included articles (2) written in English to allow readers of our article to retrace all steps of the analyses. We further chose to focus on (3) empirical articles, as our aim was to elaborate on notions of creativity addressed in empirical research. Furthermore, we focused on (4) studies on students but not on teachers' creativity or creative teaching. Additionally, we set the (5) time period to the years 2007-2019. This was a relatively current period and articles in the databases were fully maintained for the given period. ${ }^{2}$

\footnotetext{
${ }^{1}$ Please note that this article is based on preliminary work. At two PME conferences (Joklitschke et al. 2018, 2019), we have presented results for the keyword search and discussed preliminary results (for 2007-2016). According to Gough et al. (2013), those results belong to the steps of coding and mapping, which will also be introduced in this article. However, the essential part of the article at hand, especially the results (with the step of appraising) and the discussion part (with the step synthesis), goes substantially beyond these steps.

2 Please note that the MathEduc database was maintained exhaustively only until 2016 and has been shutdown since the start of 2020. Therefore, we used Education Research Complete for 2017-2019.
} 


\section{Step 4: Search}

Of particular importance were the search terms (see Joklitschke et al., 2018). For finding appropriate search terms, titles of contributions in conference proceedings of the PME from 2007 to 2016 as well as a number of manuals and encyclopedias (e.g. Carayannis, 2013; Gutiérrez et al., 2016; Kaufman \& Sternberg, 2010; Kerr, 2009; Leikin \& Sriraman, 2017a; Lerman, 2014; Lester, 2007; Runco \& Pritzker, 2011) were searched for the term creativ*. Then a full text search with creativ* in the according articles was conducted and the surrounding text passages were searched for synonyms. Terms such as originality, for example, were found frequently, but these were mostly used for further specification, not as synonyms for creativity. Finally, a list of eight search terms/strings was created: creativ*, divergent think ${ }^{*}$, innovate*, invent*, illuminat ${ }^{*}$, aha $^{*}$, bisociat $^{*}$, and overcom* fixation.

We conducted a search of different orientated databases: PsycINFO, for the field of psychology, and MathEduc as well as Education Research Complete (ERC), for mathematics education (Fig. 1). We searched titles, abstracts, and keywords (for PsycINFO, we combined each search term with math*). To narrow our search in PsycINFO to publications of higher quality and of relevance for mathematics education, we only included those articles that were published in a journal listed in the Web of Science (WoS) in the area of education (categories were education, educational research, education scientific disciplines, and special education), which resulted in 223 hits. Since the WoS only includes a small number of journals in mathematics education, we used MathEduc and ERC to search within the $\mathrm{A}^{*}$ and $\mathrm{A}$ ranked journals in mathematics education research (Törner \& Arzarello, 2012)-leading to 250 hits.

\section{Step 5: Screening}

We initially screened all 473 articles (223 from PsycINFO/WoS, 250 from MathEduc and ERC) by reading (a) titles, abstracts, and keywords and excluding those articles that did not address creativity in mathematics or (b) did not meet the criteria 2-4 from step 3. The screening process led to the inclusion of a total of 51 articles (see Fig. 1) in the final analysis. This reduction to only $11 \%$ of the first round of data (51 out of $223+250$

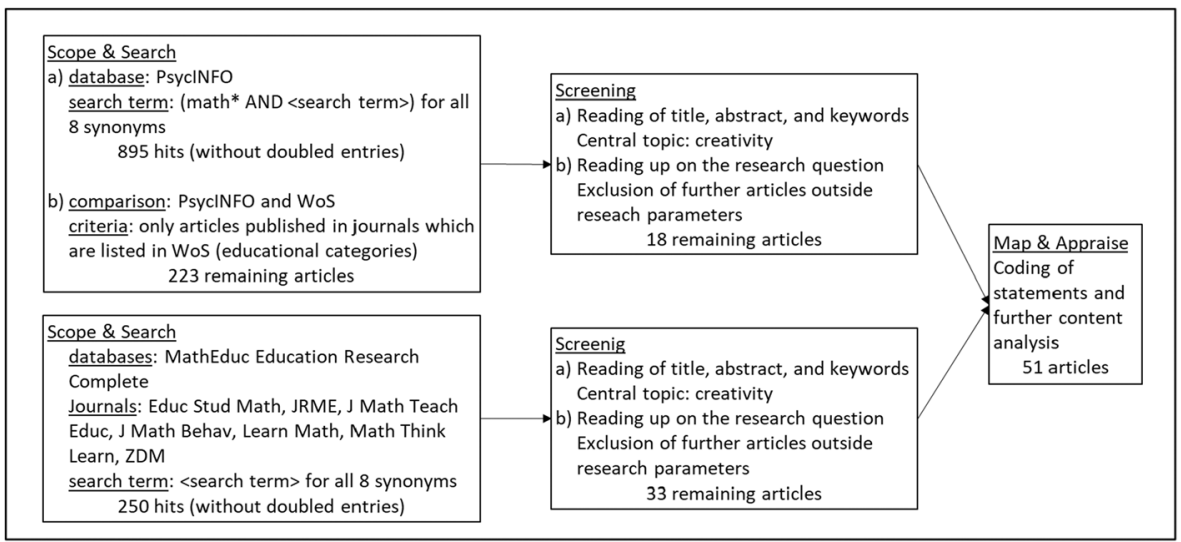

Fig. 1 Flowchart of the search process for the systematic literature review 
articles) is remarkable. This high number of exclusions had mostly one reason: by using search terms like invent ${ }^{*}$, articles were also found on many kinds of inventories that have nothing to do with creativity - those articles were sorted out right at the beginning and before our analysis started. These 51 articles were found in 13 different journals. The journals with the highest numbers of articles were ZDM-Mathematics Education, Thinking Skills and Creativity, and Educational Studies in Mathematics (see Table 1). ZDM published two issues dedicated to the topic of creativity within the time period of our review_which explains the large number of articles included.

\section{Step 6: Code}

In line with our research aim, after reading the articles intensively, we concentrated our analyses on those sections from the introductions up to the methodological considerations. For the preparation of the content analysis, so-called statements were coded. In this article, a statement is defined as a proposition made on creativity in a mathematical context in conjunction with a reference. For clarification, the following are an example and a counter-example. "Ervynck (1991) outlined the development of creativity in mathematics as a series of stages with algorithmic activity as precursors to creative activities" Mann et al. (2017, p. 70). In contrast, although it addresses an understanding of creativity, the following quote by Mann et al. (2017, p. 70) was not included in our coding, because there is no reference that would make a theoretical orientation explicit: "While fluency is considered the number of responses generated, flexibility is focused on the variety of approaches that an individual is able to use in solving a problem." This strict rule protects the data against the influence of the personal opinion of authors, and instead captures statements that were based on underlying theories. Of course, scholars present new theories or conceptualizations without reference to other theories. Due to the parameters we established, such theoretical propositions were not included in our

Table 1 Number of articles under review sorted by publishing journal

\begin{tabular}{ll}
\hline Journal & Number of articles \\
\hline ZDM - Mathematics Education & 16 \\
Thinking Skills and Creativity & 10 \\
Educational Studies in Mathematics & 7 \\
The Journal of Mathematical Behavior & 6 \\
For the Learning of Mathematics & 3 \\
High Ability Studies & 2 \\
Asia Pacific Education Review & 1 \\
Gifted Child Quarterly & 1 \\
Innovations in Education and Teaching International & 1 \\
Journal of Mathematics Teacher Education & 1 \\
Technology, Pedagogy and Education & 1 \\
Eurasia Journal of Mathematics, Science \& Technology Education & 1 \\
Teaching in Higher Education & 1
\end{tabular}


coding method. In the discussion, we will elaborate why this restriction has little disadvantage for answering our research question.

In a second step, the statements were sorted into the following two categorizations: their character (Joklitschke et al., 2018) and their addressee (Joklitschke et al., 2019). We identified three characters of statements: definition, components, and description. Definition statements are sentences where the author clearly expresses that the respective statement is a definition. Components statements are sentences describing creativity through a closed list of specific properties, and description statements contain more of a loose collection of properties. In total, 303 statements were coded for the purpose of our article: 37 definition statements, 63 component statements, and 203 description statements were included in the further analysis. Focusing on the addressee, we analyzed and summarized what strand was addressed, according to Rhodes' model of the 4 Ps of creativity, for the first content analysis of the statements.

\section{Step 7 and 8: Map and Appraise}

The mapping step forms the basis for a content analysis of the coded statements. The statements were clustered inductively with regard to the notions of creativity, using statements from the category definitions as a starting point. As an example, Fig. 2 illustrates the mapping process. The mapping had two goals: it gave a rough overview of the different notions of creativity and their distribution, and it built the basis for the synthesis in the following step, in which each notion could then be further analyzed individually according to different aspects (details below in the step appraise). We set a lower limit for the number of statements to create a notion: at least five statements from two articles with coherent theoretical references needed to be coded for us to incorporate them as notions of creativity in our review. Thus, such leftover statements were incorporated in a residual category.

In the appraise step, the different notions of creativity in mathematics were evaluated to investigate their theoretical foundations and their usage. Since the step of an appraisal is often interpretative, and at the same time it was difficult to find hard-tooperate criteria to evaluate different notions, a few points of convergence will be mentioned here; for usage, we started by evaluating the temporal perspective: first, we looked at how long (since when) the respective notion was used in the articles

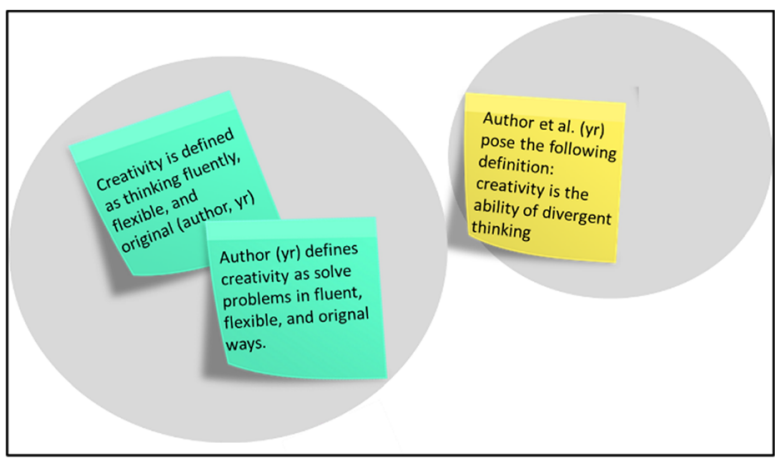

Fig. 2 Example of mapping process with three notional statements 
integrated in our review, and second, we investigated the geographical spread, evaluating the dissemination of the respective notion among different research groups.

\section{Steps 9 and 10: Synthesize and Communicate}

The synthesis represents the final product of the literature review by bringing together the results and answering the research question. According to Gough et al. (2013), the step communication refers to publishing the generated findings. Both synthesis and communication will be presented in the results and discussion section.

\section{Results}

In this section, we present - in line with our research question - the notions of creativity and underlying theoretical foundations we found. The content analysis of the statements revealed five different notions. Since the statements within the notions are aimed at different addressees, we analyzed the contents of the statements along two categorizations: the notion of creativity (see list below) and the respective addressees with reference to Rhodes (with a focus on person, process, product, or press). Figure 3 shows the number of the coded statements in each notion. The interrater reliability for coding (Brennan and Prediger 1981) was $k=0.87$, which can be considered very good.

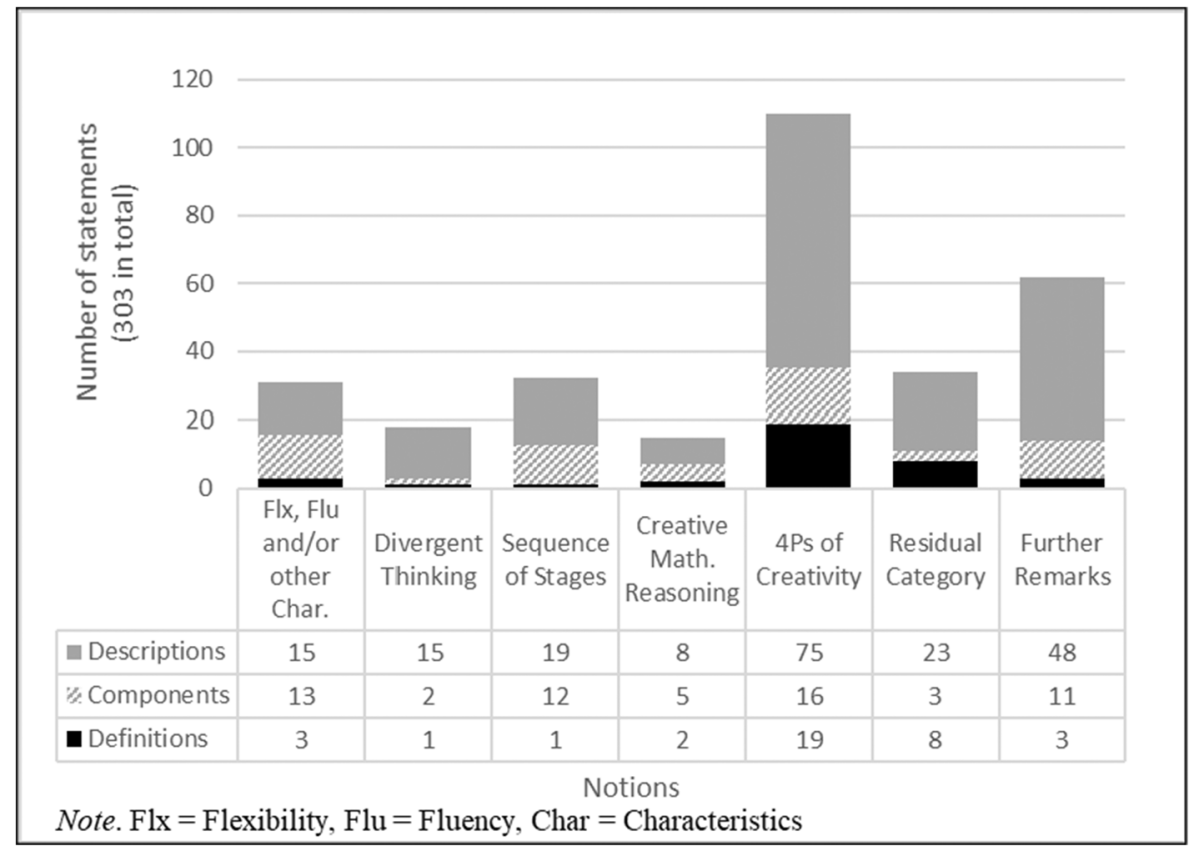

Fig. 3 Distribution of the coded statements with respect to their notion. The "residual category" and "further remarks" do not represent a notion, but arose inductively from the mapping step. Explanations will follow in the text 


\section{Creativity as Flexibility, Fluency, and/or Other Characteristics}

Thirty-one statements in our review addressed creativity as flexibility, fluency, and/or other characteristics - as a set of specific and typical characteristics. For example, Levav-Waynberg and Leikin (2012, p. 76) refer to "Torrance's (1974) definition of creativity, according to which creativity is based on four mutually related components: fluency, flexibility, novelty, and elaboration." In this statement, none of the 4 PS (Rhodes, 1961) is addressed specifically. Similarly, van Harpen and Presmeg (2013, p. 120) propose a description of creativity which is independent from the 4 Ps: "In the year 1950, Guilford and his associates hypothesized that fluency, flexibility, and originality would be three important aspects of creativity (Guilford, 1959)." Other scholars make the relationship to the 4 Ps of creativity explicit, such as Pitta-Pantazi et al. (2013, p. 200), who relate a description of creativity to products: "[Researchers] have argued that a creative product can be judged by criteria such as fluency, flexibility, originality, elaboration and appropriateness (e.g., Leikin, 2009; Silver, 1997; Torrance, 1974)." Here, fluency and flexibility are complemented with originality, elaboration, and appropriateness. For example, one statement by Leikin and Lev (2013, p. 184) does not point to originality but to novelty and elaboration: "Torrance (1974) suggested a definition of creativity that served as the basis for a battery of tests designed to identify creativity. The definition was based on four related components: fluency, flexibility, novelty, and elaboration."

Historically, this notion of creativity goes back to the psychologist and intelligence researcher Joy Paul Guilford. He was one of the first scholars who did not describe intelligence using a hierarchical model (a model with one single general intelligence factor to which other divisions are hierarchically subordinated), but developed a threedimensional model and worked out 120 factors (Guilford, 1967) of intelligence (and later Guilford, 1977 extended the model to 150 factors). His model includes divergent production, which, according to Guilford, is strongly associated with creativity and can be characterized by the above-mentioned factors, fluency, flexibility, originality, and elaboration (Guilford, 1956, 1967). To assess creativity, Guilford (1967) developed the Brick Uses test. Later, Torrance used this conceptualization to develop the frequently used TTCT (Torrance Test of Creative Thinking) (Torrance, 1966, 1974). Since this test addresses general creativity, there was a growing interest in developing domainspecific adaptations. For research in mathematics education, Leikin (2009) developed an instrument for evaluating mathematical creativity by adapting parts of the TTCT, resulting in the idea of Multiple Solution Tasks (MSTs) - mathematical tasks that are to be solved in different ways (Leikin, 2009; Leikin \& Lev, 2007).

In summary, we see this notion with its underlying theoretical background as highly significant for mathematics education research. First, it is theoretically well located, and thus, the historical origins can be traced back well. Guildford's contribution can be considered enriching and significant for the mathematics education community. Second, many researchers in mathematics education have been working continually with this notion. We found the first references around 2007 (Leikin \& Lev, 2007), and it is still used to capture creativity beyond the considered period of time (Pitta-Pantazi et al., 2018). Many scholars in mathematics education refer to these fundamentals not only to investigate creativity itself; they also use MSTs as tools to set up and validate models of giftedness (see, e.g. Kattou et al., 2015; Kontoyianni et al., 2013). 


\section{Creativity as Divergent Thinking}

In this notion, we grouped 18 statements that related creativity to divergent thinking. Kim et al. (2016, p. 39) explain that "creativity is defined in a number of ways by scholars, including the capacity to produce ideas related to divergent thinking rather than convergent thinking (Guilford, 1959)" and refer to creativity as they write about the capacity of a person. Barak (2009, p. 346) also refers to Guilford: "Guilford's (1963) distinction between convergent thinking and divergent thinking was genuinely a milestone in the research on creativity during the past half century." With regard to Rhodes' 4 Ps of creativity, Barak does not mention specifically what is addressed. As indicated in these two statements, the concept of divergent thinking stems from Guilford's research (1967), and he describes divergent production as one of the most important factors in creative thinking. Further, for some scholars, only divergent thinking exclusively describes creativity, and for others, the interplay of divergent and convergent thinking is essential for creativity. For example, Kim et al.'s statement at the beginning of this paragraph puts more emphasis on divergence, whereas Barak (2009) emphasizes the interplay between convergent and divergent thinking.

In summary, we found 18 statements about creativity as divergent thinking in ten articles from research groups worldwide (Asia, Europe, America). However, the distribution of the statements over many articles indicates that this notion of creativity was not in particular focus. Yet, this notion has a strong underlying theory, and we think that it would be valuable for mathematics education research to examine this perspective further.

\section{Creativity as a Sequence of Stages}

Thirty-two statements from twelve articles referred to creativity as a sequence of stages. Liljedahl (2013, p. 254), for example, describes this sequence of stages, referring to Poincaré (1948): "So deep were [Poincaré's] insights into his acts of invention and discovery that it could be said that he not so much described the characteristics of mathematical creativity, as defined them", where "acts of intention and discovery" refers to creativity as a process (Rhodes, 1961). In this statement, Liljedahl (2013) deliberately uses the description of a phenomenon to define creativity. He draws on the descriptions of Poincaré (1948), who, in his talk L'Invention mathématique, reports on how he worked intensively on a mathematical problem over a long period of time and got stuck at a certain point. He describes how he suddenly had a moment of enlightenment during an everyday situation, entering a bus, and knew with absolute certainty that he could now solve the mathematical problem. In his book The art of thought, the Gestalt psychologist Graham Wallas (1926) used this observation (as well as the reports by the physicist Hermann von Helmholtz) to develop a four-stage model of the creative process that consists of the phases preparation, incubation, illumination, and verification. Hadamard (1945) then successfully transferred this model into the field of mathematics. Other stage models are also mentioned. For example, Sriraman (2009, p. 14) writes that "Ervynck (1991) described mathematical creativity in terms of three stages. $[\ldots]$ preliminary technical stage $[\ldots]$ algorithmic stage $[\ldots$, and $]$ creative activity". A total of twelve statements that describe different stage models could be coded. 
In contrast to the first notion of creativity (creativity as flexibility, fluency, and/or other characteristics, based on Guilford), this notion originates in the mathematical field. Liljedahl (2013) emphasizes that for both an absolute and a relative view on creativity "illumination is at the heart of the creative experience" (Liljedahl, 2013, p. 256). This notion has a strong underlying theory from the domain of mathematics: Hadamard's stage model. This model was referred to in sixteen statements - the other fifteen statements in this notion refer to other stage models. The eight articles that refer to Hadamard's theoretical background date from the years 2009 to 2016 and have been used by research groups from all over the world. Hence, this notion can be attributed as having significant importance for research on creativity in mathematics.

\section{Creativity in the Sense of Creative Mathematical Reasoning (CMR)}

In eight articles, 15 statements were coded that connect creativity to reasoning. Jonsson et al. (2014, p. 22) refer to Lithner (2008) and conceptualize creativity as follows: "Lithner (2008) defined CMR [creative mathematical reasoning] as fulfilling all of the following criteria: (i) Creativity; a new reasoning sequence (new to the reasoner) is created, or a forgotten one is re-created, in a way that is sufficiently fluent and flexible enough to avoid restraining fixations; (ii) Plausibility [...]; and (iii) Anchoring [...]." This notion of creativity, which is process-oriented in Rhodes's (1961) sense, is to be seen as part of a three-component system consisting of creativity, plausibility, and anchoring. For the reader, it may seem a bit perplexing that creativity is described here by creative reasoning but what we present here is a representative number of statements that share a view that addresses creative mathematical reasoning, part of which is seen as creativity. The interweaving of the hierarchies is very close, so that we include this construct here as a notion without evaluating and judging which part could stand for creativity and which not. Lithner (2008) contrasts the theoretical background of CMR to imitative reasoning, which includes memorized reasoning (MR) and algorithmic reasoning (AR), the latter referring to using a known procedure. Boesen et al. (2010, p. 95) pose a statement about components that builds on this distinction and develop it further: "Using the definitions of AR and MR two categories of CMR are defined: Reasoning that is mainly based on MR or AR but contains minor, local elements of CMR will be called local CMR while reasoning with large CMR elements is called global CMR. The latter may still include large elements of MR or AR. The local aspect was introduced by Lithner (2004) to capture the substantial empirically established differences between Local and Global CMR." This statement goes a little further and links the seemingly opposite poles of CMR and MR/AR to each other and, thus, opens up the possibility that even within creative reasoning processes, parts of memorized reasoning or algorithmic reasoning can be found.

The notion of creativity as CMR comes from a comparatively young model, which was introduced by Lithner (2008) in mathematics education. Originally, he developed this model during analyses on the subject of rote learning. Lithner (2008) describes different ways of reasoning, which he understands as a line of thought that does not necessarily have to be objectively correct. AR is thus part of imitative reasoning, which also includes the MR (for more details, see Lithner, 2008). CMR, on the other hand, involves (re-)inventing one's own solution strategies. It is important to stress that CMR is not to be equated with problem solving (Lithner, 2008); it does not necessarily 
require the characteristic of getting stuck or the individual challenge of traditional problem solving. In its first iteration, Lithner's model of CMR included the components novelty, plausibility, and mathematical foundation and was then further developed into creativity, plausibility, and anchoring (see Boesen et al., 2010). The replacement of the term novelty with the term creativity could be an indication that the term creativity is mainly associated with novelty. This indicates an emphasis on novelty in the consideration of creativity in this framework.

We found that this notion of creativity is situated in the larger framework of mathematical reasoning, which gives it a strong theoretical background. The framework does not originate from outside mathematics education (e.g. from psychology) but was developed specifically in the domain of mathematics education to account for ways of reasoning among, for instance, students. From a historical perspective, this notion is relatively new as compared to the abovementioned notions. Also noteworthy is that all of the coded statements referring to this notion point to the one research group that developed the framework originally, indicating a relatively small geographical distribution up to now. As this newer idea develops, the usefulness of this notion of creativity in the research community will be assessed.

\section{Person-, Product-, Process-, and/or Behavior-Based Notion of Creativity}

This notion of creativity has by far the most statements, 110 , and is connected to statements that focus exclusively on strands, as mentioned by Rhodes (1961) (person, product, process, press). Here, the 4 Ps of creativity not only serve as a grid for determining the addressee of creativity as in the presented notions above; they also represent a notion of creativity on its own. For example, Kim et al. (2016, p. 39) state, "Most researchers agree on a general definition of creativity as 'the ability to produce a new, high quality, and appropriate product' (Sternberg, Kaufman, \& Pretz, 2002).” A similar definition is used by Barak (2009, p. 345): "we use here a concise definition according to which creativity is the ability to produce work that is both novel (original, unexpected, imaginative) and appropriate (useful, adaptive, concerning task constraints) (Guilford, 1967; Sternberg \& Lubert [sic], 1996; Simonton, 1988, 1997)." Also, Ayas and Sak (2014, p. 195) state that creativity "is usually defined as the ability [of a person; in sense of Rhodes] to generate ideas or products that are novel and useful (Boden, 2004; Cropley, 1999; Mayer, 1999; Piffer, 2012; Plucker, Beghetto, \& Dow, 2004; Sak, 2004; Sternberg \& Lubart, 1995)".

All these statements conceptualize creativity as a characteristic of a person who is able to create a product with certain properties, expressed as "new, high quality, and appropriate," "novel and appropriate," "novel and useful," and "new and appropriate." It is worth noting that references are often made to Sternberg. Sternberg, a psychologist, presents a theory on creativity and states that "creativity is the ability to produce work that is both novel (i.e., original or unexpected) and appropriate (i.e., useful or meets task constraints; Lubart, 1994; Ochse, 1990; Sternberg, 1988b; Sternberg \& Lubart, 1991, 1995)" (Sternberg \& Lubart, 1996, p. 677). Apart from that, the many references given in the two statements above (as well as in the other statements in this notion) indicate that there is no clear origin to which the particular characteristics can be referred toalthough there is a certain consistency of content. 
Kim et al. provide another definition by referencing an understanding of creativity that involves the environment: "Creativity is defined in a number of ways by scholars, including the capacity to produce [...] new and valuable ideas or behaviors generated from interaction between a person's thinking and socio-cultural context (Csikszentmihalyi, 1996)" (Kim et al., 2016, p. 39). These ideas in this passage can be closely connected to person (capacity), product (to produce), process (behavior and thinking), and press (interaction in socio-cultural context).

Summarizing this notion of creativity, we see that statements with the collections of characteristics in the four examples quoted above seem to occur relatively frequently. They serve as a description rather than as a precise working definition, and this notion is not easy to operationalize methodologically. These lose and vague descriptions once again illustrate how broad the descriptions of creativity are. Interestingly, besides the 19 definitions included in this notion, there were rather few statements describing a closed list of specific properties (16 component statements). An example is a statement by Leu and Chiu (2015, p. 41): "The creative process [...] can be categorized into fast (automatic) and effortful (logical) thinking (Allen \& Thomas, 2011).’More statements are describing a loose collection of properties ( 75 description statements). Here, a plain example comes from Leu and Chiu (2015, p. 41) "Creative behaviors in general creative thinking may include both cognitive [...] and affective [...] components followed by the creative process of frame construction, situation consideration, learner understanding, and stream negotiation (Newton, 2013)." This could be due to the fact that no distinct theoretical foundation is referred to within this notion, and thus, the composition of individual characteristics of creativity is diverse. This great diversity is also reflected in the geographical spread - research groups from all over the world refer to this notion in their statements.

\section{Residual Category}

Thirty-four of the coded statements could not be assigned to one of the abovementioned notions for two reasons: either they were referring to more than one of the above-mentioned notions or there were too few related statements (less than five), so no notion was created. In the following paragraphs, we give examples of these uncategorized ideas.

The following statement by Sitorus and Masrayati (2016, pp. 112-113), for example, shows aspects of several notions of creativity: "Creativity is the act of conscious and unconscious thinking process that underlies scientific discovery, artistic originality, and inspiration, that has four standard indicators, namely: fluency, originality, flexibility, and elaboration (Guilford, 1967; Koestler, 1964; Siswono, 2004; Wallas 1926)." This statement focusses on processes in the sense of Rhodes (1961). However, it is a kind of hybrid: the interplay of conscious and unconscious thinking refers to the notions of creativity as a sequence of stages, with a theoretical background in Hadamard, and the indicators refer to the notion of creativity as flexibility, fluency, and/or other characteristics, which is connected to Guilford and Torrance.

Another example focuses on flexibility can be found in Chen et al. (2016, p. 248), which emphasizes mental flexibility as a key component of creativity and state, "for example, Krutetskii (1976) defined mathematical creativity as mental flexibility that enables students to think outside the box and apply novel approaches to solve problems 
(Haylock, 1985, 1987, 1997; Sriraman, 2004)." In Rhodes' sense, this statement emphasizes the process aspect. Here, creativity is described as inherently related to problem solving. However, there were not enough statements referring to the aspect of mental flexibility to constitute a separate notion. The same limitation applies to the following statement, which is also about flexibility. However, here it is represented as a component together with knowledge. In the article by Leikin and Lev (2013), a statement from the category components was extracted: "Kwon et al. (2006) proposed two major components of mathematical creativity: the creation of new knowledge and flexible problem-solving abilities" (p. 185).

A few statements clearly go back to Haylock's model of overcoming fixation and divergent production. Thus, Huang et al. (2017, p. 7) write: "On the other, Haylock (1987a, 1987b, 1997) argued that mathematical creativity includes two important components: overcoming fixation (OF) and divergent production (DP)." Overall, however, too few statements with this content orientation could be found, so that they do not (yet) represent an own notion.

\section{Further Remarks}

In addition to the statements that are strongly related to theory, we identified a number (specifically 62) of different statements. These are not (and this is the difference to the residual category) based on an underlying theory about creativity, because they do not describe creativity itself: Thus, they cannot form a notion. However, they do describe scopes for all the notions we found and are hence of interest. In particular, we found that creativity could either be regarded as domain-general or domain-specific. For instance, Peng et al. (2013, p. 53) suggest a distinction between domain-general and domain specific: "domain-general means that a creative individual can extract his/her creativity in any domains, whereas domain-specific means that an individual can only extract his/her creativity in a certain domain [...] (Hong \& Milgram, 2010; Silvia, Kaufman, \& Pretz, 2009)."

\section{Synthesis and Discussion}

The article presents a systematic, configurative, and inductive literature review (see Gough et al., 2013) of notions of creativity in current empirical mathematics education research. An advantage of such a systematic literature review is the transparency of the methodological approach. In addition, the parameters for the search for relevant literature allows for all relevant literature - that met our parameters exactly - to be found and included, which prevents articles from being overlooked. With the help of a systematic approach, we were able to identify five predominant notions with varying significance with regard to theoretical foundations and usage (temporal and geographical): (1) The notion of creativity through fluency, flexibility, and/or other characteristics that can be traced back to Guilford (1956) and Torrance (1974), (2) the notion of creativity as divergent thinking, which also goes back to Guilford, (3) the notion of creativity as a sequence of stages, which has its origins in mathematics (Hadamard, 1945), (4) the notion of creativity as creative mathematical reasoning, a newer idea that 
can be traced back to Lithner (2008), and (5) the person-, product-, process-, and/or behavior-based notion of creativity.

At this point, shifting the focus to the relationships between the different notions is worth considering. As shown above, the clearest connection can be drawn between the notions of creativity as (1) fluency, flexibility, and/or other characteristics and as (2) divergent thinking. Here, the obvious element of connection can be found in the historical roots of Guilford's work. In his Structure of Intellect Model, Guilford distinguishes, among other things, between divergent and convergent thinking and emphasizes the importance of both ways of thinking for creativity. In more detail, the essential factors for divergent thinking are the facets fluency, flexibility, originality, and elaboration. Although both aspects can be traced back to the same origin, considering them as separate notions seems to reflect better their different use in the theoretical discussion around current creativity research in mathematics education: With a focus on fluency, flexibility, and originality, products are mostly seen as a matter of assessing creativity. Divergent thinking, on the other hand, refers primarily to processes or characteristics of people and is more concerned with characterizing creativity. Interestingly, the notion of (4) creative mathematical reasoning also ties in with this history, but in a slightly more implicit way. Already the introductory statement described creativity as "a reasoning sequence [...] that is sufficiently fluent and flexible" (Jonsson et al., 2014 , p. 22) and therefore relates to notion (2). In the background literature, this reference is more explicit (though rarely found): "The framework of this paper amalgamates Haylock's and Silver's views and sees fluency, flexibility and novelty as key qualities when distinguishing creative reasoning from imitative reasoning" (Lithner, 2008 , p. 7). Although Guilford is not referred to in this quote, the connection is clearly recognizable. The notion of (3) creativity as sequence of stages originates from mathematics and, thus, shows no connection to the above notions. The perspective of the person-, product-, process-, and/or press-based view (4Ps) represents a unique position since it has a twofold function: On the one hand, it stands transverse to the other notions, since other notions can also implicitly address different addressees, and on the other hand, it represents a (4) notion of its own by addressing special properties of one or more of the $4 P S$.

As compared to previous overviews of research on creativity in mathematics education (e.g. Sriraman, 2009), this article's contribution lies in the identification of different notions as well as the examination of the respective underlying theories since it does not compare the literature to date in a meta-perspective way (e.g. previous reviews have been organized according to approach, such as psychometric or mystical). Our review organizes the contents of current research according to the notions of creativity, the respective background, and their usage and significance in empirical research. Of course, this article cannot illuminate the notions and respective theoretical backgrounds and origins in all detail; however, the overview provided in this article may offer a first point of entry into the research field of creativity in mathematics education.

In publications both included in and excluded from this literature review, it is consistently stated that the concept of creativity is wide-ranging (Mann, 2005; PittaPantazi, 2017; Sriraman et al., 2014). There are also statements we found in our analysis that explicitly emphasize the large number of definitions, such as the following statement by Leikin and Lev (2013): "Mann (2006) argues that there are more than 100 
contemporary definitions of creativity" (p. 184). In addition, in the analysis portion of this article, the wide variety of definitions becomes apparent explicitly_particularly in articles discussing the different combinations of the addressees of creativity, which we analyzed here with the 4 Ps of Creativity (see Rhodes, 1961). However, in the coding stage of the analysis, we noticed that there were some statements that at first glance were attributed to a person, but in further specifications, product-based characteristics were added. There seems to be a variety of interrelations and implicit causalities, such as the inference of a connection between creative products to creative people. This can easily lead to confusion and even misinterpretation. Based on this study, we would like to emphasize and encourage researchers to be sensitive and careful when drawing such inferences, to make these connections as transparent as possible, and to underpin them argumentatively.

Of course, there are some limitations to the findings, as our review could only be made under certain conditions. (1) There may be differences between the propositional content of the statements presented and the authors' conceptualization of creativity. The analysis of the statements is only intended to catalog what notions are mentioned and named. Individual statements are neither representative of the whole article included in our review nor of the respective authors' opinions. In addition to this point, it should be noted that we did not include any statements in the analysis that were not referenced. Thus, it is conceivable that the respective author's own contributions to theory development were omitted in our analysis. However, if such theoretical developments were then referred to in further publications (and thus include a reference to their origin), they were coded and included in our analysis and thus included in our review. (2) Our results are only valid in light of the framework conditions mentioned above. An extension of the time period, the inclusion of further journals, and the inclusion of books or conference proceedings could help to add to the resulting findings. The same applies to the analysis of the empirical parts of the articles. In the present review, only the statements from a portion of the articles were coded, up to the research question or the methods, respectively. In addition to the findings with respect to our research question, there are methodological outcomes of this review. Our approach contributes to further establishing the method by Gough et al. of systematic reviews in the field of mathematics education.

Looking at the trends that can be identified within the notions of creativity, different developments can be seen. The notion of creativity through fluency, flexibility, originality, and/or other characteristics originally were intended for the pure exploration and assessment of creativity. After the TTCT was adopted to the field of mathematics education research, the main focus was on the investigation of the relationship of creativity to abilities and giftedness (Kattou et al. 2013; Kontoyianni et al. 2013; Leikin \& Lev, 2013). We see that researchers continue to investigate the potentials and challenges of assessing creativity in light of this notion (Levenson et al., 2018; Liljedahl \& Rott, 2017; Schindler et al., 2018). In recent works, so-called Multiple Solution Tasks (MSTs, Leikin, 2009), originally intended to capture the concept of creativity on the basis of this framework, have also been used to address so-called "authentic" tasks, real-world situations, and "extreme" tasks, which lead to conceptual changes (Ronen, 2018). In creativity research, MSTs have become an established activity. Schindler and Lilienthal (2020), for example, use an MST to investigate mathematical creativity as a process in its phases - and connect MSTs to stage models 
of the creative process such as the ones offered by Wallas (1926) and Hadamard (1945).

The research related to the notion of creativity as a sequence of stages (with 16 statements referring to Hadamard's conceptualization) is less extensive than research on the notion of creativity through fluency, flexibility, originality, and/or other characteristics (here, 22 statements were found). Although the historical roots of the stage theories are inherent in mathematics, their use in empirical research is not yet established. One reason may be the difficulty to investigate the creative process in situ - which is methodologically challenging. Yet, one promising methodological tool to investigate the creative process in its phases has been used by Schindler and Lilienthal (2020). They illustrate how the analysis of students' eye movements, together with retrospective, stimulated-recall interviews, can shed light on the phases of the creative process, especially incubation (and what they call "mini-incubation"). Eyetracking has recently also been used in research on the notion of creativity as creative mathematical reasoning (Norqvist et al., 2019). The emerging use of eye tracking in research on creativity in mathematics (see, e.g. Schindler \& Lilienthal, 2017a; Schindler et al., 2016) reflects the perceived opportunities scholars see in this method for investigating mathematical creativity from a process view, as described by Schindler and Lilienthal (2017b).

Finally, we hope that the review we provided in this article will help researchers to navigate the diverse field of research on creativity in mathematics education research. This overview may help orient researchers who conduct empirical research on creativity in mathematics and may even help the field to systematically develop further, to counteract the "fog in talk about creativity" (Rhodes, 1961, p. 307), so that, in perspective, the creative works and processes of students could be looked at more precisely and specifically.

Funding Open Access funding enabled and organized by Projekt DEAL.

Open Access This article is licensed under a Creative Commons Attribution 4.0 International License, which permits use, sharing, adaptation, distribution and reproduction in any medium or format, as long as you give appropriate credit to the original author(s) and the source, provide a link to the Creative Commons licence, and indicate if changes were made. The images or other third party material in this article are included in the article's Creative Commons licence, unless indicated otherwise in a credit line to the material. If material is not included in the article's Creative Commons licence and your intended use is not permitted by statutory regulation or exceeds the permitted use, you will need to obtain permission directly from the copyright holder. To view a copy of this licence, visit http://creativecommons.org/licenses/by/4.0/.

\section{References}

Albert, R. S., \& Runco, M. A. (1999). A history of research on creativity. In R. J. Sternberg (Ed.), Handbook of creativity (pp. 16-31). Cambridge Univ. Press.

Ayas, M. B., \& Sak, U. (2014). Objective measure of scientific creativity: Psychometric validity of the Creative Scientific Ability Test. Thinking Skills and Creativity, 13, 195-205.

Barak, M. (2009). Idea focusing versus idea generating: A course for teachers on inventive problem solving. Innovations in Education and Teaching International, 46(4), 345-356. 
Boesen, J., Lithner, J., \& Palm, T. (2010). The relation between types of assessment tasks and the mathematical reasoning students use. Educational Studies in Mathematics, 75(1), 89-105.

Brennan, R. L., \& Prediger, D. J. (1981). Coefficient kappa: Some uses, misuses, and alternatives. Educational and Psychological Measurement, 41(3), 687-699.

Carayannis, E. G. (Ed.). (2013). Encyclopedia of creativity, invention, innovation and entrepreneurship. Springer Dordrecht.

Chen, Y.-W., Chang, W.-H., \& Kuo, C.-C. (2016). A comparative study of the divergent problem solving abilities of mathematically and scientifically talented students and nongifted students. Thinking Skills and Creativity, 22, 247-255.

Clements, M. A. (2013). Past, present and future dimensions of mathematics education: Introduction to the third international handbook of mathematics education. In M. A. Clements, A. J. Bishop, \& C. Keitel (Eds.), Springer international handbooks of education: Vol. 27. Third international handbook of mathematics education (pp. v-xi). Springer.

Gough, D., Oliver, S., \& Thomas, J. (2013). Learning from research: Systematic reviews for informing policy decisions: A quick guide. A paper for the Alliance for Useful Evidence. Nesta.

Guilford, J. P. (1956). The structure of intellect. Psychological Bulletin, 53(4), 267-293.

Guilford, J. P. (1967). The nature of human intelligence. McGraw-Hill.

Guilford, J. P. (1977). Way beyond the IQ: Guide to improving intelligence and creativity. Creative Education Foundation.

Gutiérrez, Á., Leder, G. C., \& Boero, P. (Eds.). (2016). The second handbook of research on the psychology of mathematics education: The journey continues. Sense Publishers.

Hadamard, J. (1945). The psychology of invention in the mathematical field: How creativity is tapped in science, the unconscious mind and discovery, intuition vs. In Verbal reasoning, Poincaré's forgetting hypothesis, creative techniques of Einstein, Pascal, Wiener and others. Dover Publications.

Hersh, R., \& John-Steiner, V. (2017). The origin of insight in mathematics. In R. Leikin \& B. Sriraman (Eds.), Advances in mathematics education. Creativity and giftedness: Interdisciplinary perspectives from mathematics and beyond (pp. 135-146). Springer International Publishing.

Huang, P.-S., Peng, S.-L., Chen, H.-C., Tseng, L.-C., \& Hsu, L.-C. (2017). The relative influences of domain knowledge and domain-general divergent thinking on scientific creativity and mathematical creativity. Thinking Skills and Creativity, 25, 1-9.

Joklitschke, J., Rott, B., \& Schindler, M. (2018). Theories about mathematical creativity in contemporary research: A literature review. In E. Bergqvist, M. Österholm, C. Granberg, \& L. Sumpter (Eds.), Proceedings of the 42nd Conference of the International Group for the Psychology of Mathematics Education: PME 42 (Vol. 3, pp. 171-178). PME.

Joklitschke, J., Rott, B., \& Schindler, M. (2019). Notions, definitions, and components of mathematical creativity: An overview. In M. Graven, H. Venkat, A. A. Essien, \& P. Vale (Eds.), Proceedings of the $43^{\text {rd }}$ Conference of the International Group for the Psychology of Mathematics Education: PME 43 (Vol. 2, pp. 440-447). PME.

Jones, K., \& Tzekaki, M. (2016). Research on the teaching and learning of geometry. In Á. Gutiérrez, G. C. Leder, \& P. Boero (Eds.), The second handbook of research on the psychology of mathematics education: The journey continues (pp. 109-149). Sense Publishers.

Jonsson, B., Norqvist, M., Liljekvist, Y., \& Lithner, J. (2014). Learning mathematics through algorithmic and creative reasoning. The Journal of Mathematical Behavior, 36, 20-32.

Kattou, M., Kontoyianni, K., Pitta-Pantazi, D., \& Christou, C. (2013). Connecting mathematical creativity to mathematical ability. ZDM - Mathematics Education, 45(2), 167-181.

Kattou, M., Christou, C., \& Pitta-Pantazi, D. (2015). Mathematical creativity or general creativity? In K. Kaiser \& N. Vondrová (Chairs), CERME9: Proceedings of the ninth congress of the European Society for Research in Mathematics Education. Prague: Czech Republic.

Kaufman, J. C., \& Sternberg, R. J. (Eds.). (2010). Cambridge handbooks in psychology. The Cambridge handbook of creativity. Cambridge University Press. Retrieved from http://www.loc.gov/catdir/ enhancements/fy1005/2010000993-b.html.

Kerr, B. A. (2009). Encyclopedia of giftedness, creativity, and talent. Sage Publications.

Kim, M. K., Roh II, S., \& Cho, M. K. (2016). Creativity of gifted students in an integrated math-science instruction. Thinking Skills and Creativity, 19, 38-48.

Kontoyianni, K., Kattou, M., Pitta-Pantazi, D., \& Christou, C. (2013). Integrating mathematical abilities and creativity in the assessment of mathematical giftedness. Psychological Test and Assessment Modeling, 55(3), 289-315. 
Leikin, R. (2009). Exploring mathematical creativity using multiple solution tasks. In R. Leikin, A. Berman, \& B. Koichu (Eds.), Creativity in mathematics and the education of gifted students (pp. 129-145). Sense Publishers.

Leikin, R., \& Lev, M. (2007). Multiple solution tasks as a magnifying glass for observation of mathematical creativity. In Proceedings of the Conference of the International Group for the Psychology of Mathematics Education. Seoul.

Leikin, R., \& Lev, M. (2013). Mathematical creativity in generally gifted and mathematically excelling adolescents: What makes the difference? ZDM - Mathematics Education, 45(2), 183-197.

Leikin, R., \& Pitta-Pantazi, D. (2013). Creativity and mathematics education: The state of the art. ZDMMathematics Education, 45(2), 159-166.

Leikin, R., \& Sriraman, B. (2017a). Creativity and giftedness: Interdisciplinary perspectives from mathematics and beyond. Springer.

Leikin, R., \& Sriraman, B. (2017b). Introduction to interdisciplinary perspectives to creativity and giftedness. In R. Leikin \& B. Sriraman (Eds.), Advances in mathematics education. Creativity and giftedness: Interdisciplinary perspectives from mathematics and beyond (pp. 1-3). Springer International Publishing.

Leikin, R., Levav-Waynberg, A., \& Guberman, R. (2011). Employing multiple solution tasks for the development of mathematical creativity: Two comparative studies. In M. Pytlak, T. Rowland, \& E. Swoboda (Eds.), Cerme7: Proceedings of the seventh congress of the European Society for Research in Mathematics Education (pp. 1094-1103). University of Rzeszów.

Lerman, S. (2014). Encyclopedia of mathematics education. Springer.

Lester, F. (2007). Second handbook of research on mathematics teaching and learning. National Council of Teachers of Mathematics.

Leu, Y.-C., \& Chiu, M.-S. (2015). Creative behaviours in mathematics: Relationships with abilities, demographics, affects and gifted behaviours. Thinking Skills and Creativity, 16, 40-50.

Levav-Waynberg, A., \& Leikin, R. (2012). The role of multiple solution tasks in developing knowledge and creativity in geometry. The Journal of Mathematical Behavior, 31(1), 73-90.

Levenson, E., Swisa, R., \& Tabach, M. (2018). Evaluating the potential of tasks to occasion mathematical creativity: Definitions and measurements. Research in Mathematics Education, 20(3), 273-294.

Liljedahl, P. (2013). Illumination: An affective experience? ZDM-Mathematics Education, 45(2), $253-265$.

Liljedahl, P., \& Rott, B. (2017). Creative process vs. creative product: Challenges with measuring creativity. In B. Kaur, W. K. Ho, T. L. Toh, \& B. H. Choy (Eds.), Proceedings of the $41^{\text {st }}$ conference of the International Group for the Psychology of Mathematics Education: PME 41 (Vol. 3, pp. 161-168). National Institute of Education, Nanyang Technological University.

Lithner, J. (2008). A research framework for creative and imitative reasoning. Educational Studies in Mathematics, 67(3), 255-276.

Mann, E. L. (2005). Mathematical creativity and school mathematics: Indicators of mathematical creativity in middle school students (Doctoral dissertation). University of Connecticut. Retrieved from http://www. gifted.uconn.edu/siegle/Dissertations/Eric\%20Mann.pdf.

Mann, E. L., Chamberlin, S. A., \& Graefe, A. K. (2017). The prominence of affect in creativity: Expanding the conception of creativity in mathematical problem solving. In R. Leikin \& B. Sriraman (Eds.), Advances in mathematics education. Creativity and giftedness: Interdisciplinary perspectives from mathematics and beyond (pp. 57-73). Springer.

National Council of Teachers of Mathematics. (2005). Principles and standards for school mathematics (4. print). Author.

Nilsson, P., Schindler, M., \& Bakker, A. (2018). The nature and use of theories in statistics education. In D. Ben-Zvi, K. Makar, \& J. Garfield (Eds.), Springer international handbooks of education. International handbook of research in statistics education (pp. 359-386). Springer International Publishing.

Norqvist, M., Jonsson, B., Lithner, J., Qwillbard, T., \& Holm, L. (2019). Investigating algorithmic and creative reasoning strategies by eye tracking. The Journal of Mathematical Behavior, 55.

OECD. (2014). Pisa 2012 results: Creative problem solving: Students' skills in tackling real-life problems (Vol. 5). Author.

Oxford University Press. (2019). Oxford learner's dictionary of academic English: notion. Retrieved from https://www.oxfordlearnersdictionaries.com/definition/academic/notion

Peng, S.-L., Cherng, B.-L., Chen, H.-C., \& Lin, Y.-Y. (2013). A model of contextual and personal motivations in creativity: How do the classroom goal structures influence creativity via self-determination motivations? Thinking Skills and Creativity, 10, 50-67.

Pitta-Pantazi, D. (2017). What have we learned about giftedness and creativity?: An overview of a five years journey. In R. Leikin \& B. Sriraman (Eds.), Advances in mathematics education. Creativity and 
giftedness: Interdisciplinary perspectives from mathematics and beyond (pp. 201-223). Springer International Publishing.

Pitta-Pantazi, D., Sophocleous, P., \& Christou, C. (2013). Spatial visualizers, object visualizers and verbalizers: Their mathematical creative abilities. ZDM - Mathematics Education, 45(2), 199-213.

Pitta-Pantazi, D., Kattou, M., \& Christou, C. (2018). Mathematical creativity: Product, person, process and press. In F. M. Singer (Ed.), ICME-13 monographs. Mathematical creativity and mathematical giftedness: Enhancing creative capacities in mathematically promising students (pp. 27-53). Springer.

Poincaré, H. (1948). Science and method (Dover ed.). Dover.

Rhodes, M. (1961). An analysis of creativity. The Phi Delta Kappan, 42(7), 305-310.

Ronen, I. (2018). "Authentic tasks" and "extreme tasks": Potential approaches to overcoming incorrect responses in conservation tasks. International Journal of Science and Mathematics Education, 16(7), 1337-1354.

Royal Literary Fund. (2020). What is a literature review? Retrieved from https://www.rlf.org.uk/resources/ what-is-a-literature-review/

Runco, M. A. (2014). Creativity: Theories and themes: Research, development, and practice. Academic Press.

Runco, M. A., \& Pritzker, S. R. (Eds.). (2011). Encyclopedia of creativity (2nd ed.). Academic Press/Elsevier.

Schindler, M., Joklitschke, J., \& Rott, B. (2018). Mathematical creativity and its subdomain-specifity: Investigating the appropriateness of solutions in Multiple Solution Tasks. In F. M. Singer (Ed.), Mathematical creativity and mathematical giftedness: Enhancing creative capacities in mathematically promising students (pp. 115-142). Springer International Publishing.

Schindler, M., Lilienthal, A. J., Chadalavada, R. T., \& Ögren, M. (2016). Creativity in the eye of the student: Refining investigations of mathematical creativity using eye tracking goggles. In C. Csíkos, A. Rausch, \& J. Szitányi (Eds.), Proceedings of the $40^{\text {th }}$ Conference of the International Group for the Psychology of Mathematics Education: PME40 (Vol. 4, pp. 163-170). PME.

Schindler, M., \& Lilienthal, A. J. (2017a). Eye-tracking and its domain-specific interpretation: A stimulated recall study on eye movements in geometrical tasks. In B. Kaur, W. K. Ho, T. L. Toh, \& B. H. Choy (Eds.), Proceedings of the $41^{\text {st }}$ Conference of the International Group for the Psychology of Mathematics Education: PME 41 (Vol. 4, pp. 1153-160). National Institute of Education, Nanyang Technological University.

Schindler, M., \& Lilienthal, A. J. (2017b). Eye-tracking as a tool for investigating mathematical creativity from a process-view. In D. Pitta-Pantazi (Ed.), Proceedings of the $10^{\text {th }}$ International Conference on Mathematical Creativity and Giftedness: MCG 10 (pp. 45-50). Department of Education, University of Cyprus.

Schindler, M. \& Lilienthal, A. J. (2020). Students' creative process in mathematics: Insights from eyetracking-stimulated recall Interview on students' work on multiple solution tasks. International Journal of Science and Mathematics Education, 18(8), 1565-1586.

Sheffield, L. J. (2013). Creativity and school mathematics: Some modest observations. ZDM-Mathematics Education, 45(2), 325-332.

Singer, F. M. (Ed.). (2018). ICME-13 monographs. Mathematical creativity and mathematical giftedness: Enhancing creative capacities in mathematically promising students. Springer.

Sitorus, J., \& Masrayati. (2016). Students' creative thinking process stages: Implementation of realistic mathematics education. Thinking Skills and Creativity, 22, 111-120.

Sriraman, B. (2005). Are giftedness and creativity synonyms in mathematics?: An analysis of constructs within the professional and school realms. The Journal of Secondary Gifted Education, 17(1), $20-36$.

Sriraman, B. (2009). The characteristics of mathematical creativity. ZDM-Mathematics Education, 41(1-2), $13-27$.

Sriraman, B., Haavold, P., \& Lee, K. (2014). Creativity in mathematics education. In S. Lerman (Ed.), Encyclopedia of mathematics education (pp. 109-115). Springer.

Sternberg, R. J., \& Lubart, T. I. (1996). Investing in creativity. American Psychologist, 51(7), 677-688.

Sternberg, R. J., \& Lubart, T. I. (1999). The Concept of Creativity: Prospects and Paradigms. In R. J. Sternberg (Ed.), Handbook of creativity (pp. 3-15). Cambridge Univ. Press.

The Writing Center. (2020). Literature reviews. Retrieved from https://writingcenter.unc.edu/tips-and-tools/ literature-reviews/

Törner, G., \& Arzarello, F. (2012). Grading mathematics education research journals. EMS Newsletter, 86, 52-54.

Torrance, E. P. (1966). The Torrance tests of creative thinking: Norms; technical manual research edition; verbal tests, forms $A$ and $B$; figural tests, forms $A$ and B. Personnel Press.

Torrance, E. P. (1974). Torrance tests of creative thinking. Scholastic Testing Service. 
Van Harpen, X. Y., \& Presmeg, N. C. (2013). An investigation of relationships between students' mathematical problem-posing abilities and their mathematical content knowledge. Educational Studies in Mathematics, 83(1), 117-132.

Wallas, G. (1926). The art of thought. Harcourt Brace.

Wyse, D., \& Ferrari, A. (2015). Creativity and education: Comparing the national curricula of the states of the European Union and the United Kingdom. British Educational Research Journal, 41(1), 30-47. 